ISSN 0103-5150

Fisioter. Mov., Curitiba, v. 26, n. 3, p. 515-524, jul./set. 2013

Licenciado sob uma Licença Creative Commons

\title{
A aquisição da motricidade em crianças portadoras de Síndrome de Down que realizam fisioterapia ou praticam equoterapia
}

\author{
The acquisition of motor skills in children with Down syndrome \\ who perform physical therapy or practice hippotherapy
}

\author{
Jamili Anbar Torquato ${ }^{[a]}$, Aline Féria Lança ${ }^{[b]}$, Décio Pereira ${ }^{[b]}$, Felipe Gonzalez Carvalho ${ }^{[b]}$, \\ Roberta Dutra da Silva ${ }^{[b]}$ \\ [a] Doutora em Ciências pela Faculdade de Medicina de São Paulo (FMUSP), docente dos cursos de Graduação e Pós- \\ -Graduação da Universidade Cruzeiro do Sul (Unicsul), coordenadora do curso de Pós-Graduação em Fisioterapia \\ Cardiorrespiratória e Hospitalar da mesma instituição, São Paulo, SP - Brasil, e-mail: jamilianbar@yahoo.com \\ [b] Fisioterapeutas pela Universidade Cruzeiro do Sul (Unicsul), São Paulo, SP - Brasil, e-mails: line.pqna@hotmail.com, \\ morenoclubber@hotmail.com, feekrvalho@yahoo.com.br, robertadutra2003@hotmail.com
}

Resumo

Introdução: 0 equilíbrio corporal é um processo complexo envolvendo recepção e integração de estímulos sensoriais integrando as informações provenientes do sistema vestibular, dos receptores visuais e do sistema somatossensorial. Objetivo: Verificar a aquisição de marcos motores em crianças portadoras de Síndrome de Down que realizam a equoterapia ou fisioterapia convencional. Materiais e métodos: Estudo transversal que contou com 33 indivíduos portadores de Síndrome de Down com idade entre 4 e 13 anos, de ambos os sexos, divididos em 2 grupos: Grupo 1 - equoterapia; Grupo 2 - fisioterapia em solo. A motricidade global, o equilíbrio estático e o dinâmico foram avaliados com uso da Escala de Desenvolvimento Motor (EDM). Utilizou-se um questionário para relatar a aquisição de marcos motores, prováveis alterações na acuidade auditiva, visual e/ou posturais, força muscular e o tempo de tratamento. Resultados: Para analise das variáveis, realizou-se o teste de Shapiro-Wilk, o teste de Qui-Quadrado e o teste Exato de Fisher, o teste te ANOVA seguido de post hoc de Bonferroni; o nível de significância foi 0,05. As aquisições dos marcos motores nas crianças portadoras de Síndrome de Down apresentam atraso considerável em comparação com crianças com desenvolvimento normal $\mathrm{p}<0,05$. As crianças que realizam fisioterapia apresentam melhor equilíbrio estático e dinâmico do que indivíduos que realizam 
equoterapia $\mathrm{p}<0,05$. Conclusão: A fisioterapia convencional teve influência positiva na obtenção das aquisições motoras e do equilíbrio estático e dinâmico em portadores de Síndrome de Down.

Palavras-chave: Síndrome de Down. Fisioterapia. Desenvolvimento infantil.

\section{Abstract}

Introduction: Body balance is a complex process involving reception and integration of sensory stimuli integrating the information from the vestibular system, the visual receptors and the somatosensory system. Objective: To investigate the acquisition of motor milestones in children with Down syndrome who perform equine therapy or physical therapy. Materials and methods: Cross-sectional study included 33 individuals with Down syndrome, aged 4 to 13 years, of both sexes divided into two groups: Group 1 - hippotherapy; Group 2 - physiotherapy in soil. Motility global, static and dynamic balance were assessed using the Scale of Motor Development (EDM). We used a questionnaire to report the acquisition of motor milestones, likely changes in hearing acuity, visual and/or postural, muscular strength and treatment time. Results: To examine the variables held the Shapiro-Wilk test, the Chi-Square test and Fisher's exact test, ANOVA followed by Bonferroni post hoc and the significance level was 0.05. The acquisition of motor milestones in children with Down syndrome have considerable delay compared to children with normal development $p<0.05$. Children who perform physiotherapy feature both static equilibrium as the dynamic better than individuals performing hippotherapy $p<0.05$. Conclusion: The conventional physiotherapy had positive influence in getting their motor skills and static and dynamic balance in patients with Down syndrome.

Keywords: Down syndrome. Physical therapy. Child development.

\section{Introdução}

A Síndrome de Down é uma condição genética causada pela trissomia do cromossomo 21 e que leva a uma distribuição cromossômica inadequada durante a fase de meiose (1). Cada célula do individuo normal possui 46 cromossomos, estes estão divididos em 23 pares; no portador da Síndrome de Down, o par de número 21 possui um cromossomo a mais, resultando em 47 cromossomos (2).

É esperado atraso no desenvolvimento motor em indivíduos com Síndrome de Down (3). Em indivíduos normais, ao nascimento, o Sistema Nervoso Central (SNC) ainda não está completamente desenvolvido, portanto ele é capaz de perceber o mundo apenas por meio dos sentidos; esse caso, os estímulos do meio externo são capazes de alterar o SNC, permitindo a evolução do indivíduo em um processo de aprendizagem que oportuniza melhor adaptação ao meio em que vive. Já no individuo com Síndrome de Down, esse desenvolvimento depende da biologia, do comportamento e do ambiente e não apenas da maturação do sistema nervoso (4).

As informações provenientes do sistema vestibular, dos receptores visuais e do sistema somatossensorial que envolvem a recepção dos estímulos e sua integração contribuem para o desenvolvimento do equilíbrio estático e dinâmico nos indivíduos que, com base nessas informações, irão adaptar-se para aquisição de marcos motores (5).

0 tratamento fisioterapêutico está voltado para a elaboração de propostas que estejam de acordo com as necessidades do paciente e com os problemas referentes aos ajustes posturais frequentes na Síndrome de Down, como os atrasos motores - principalmente o sentar e o ficar em pé. Dessa maneira, a fisioterapia se propõe realizar treino de marcha, mudanças transposturais, equilíbrio estático e dinâmico mediante técnicas e recursos específicos em solo (6). Na equoterapia, os movimentos tridimensionais proporcionados pela andadura do cavalo despertam no corpo do praticante, portador de necessidades especiais, uma grande quantidade de estímulos sensoriais e neuromusculares que vão interferir diretamente no desenvolvimento global e na aquisição de habilidades motoras, facilitando a construção de uma vida social produtiva, por meio da realização independente das atividades de vida diária, laborais, de lazer e esportivas (7).

Cavalgar é por si só um estímulo para o equilíbrio, mas algumas manobras podem ser utilizadas 
para aumentar a quantidade de estímulos: pode-se pedir ao praticante que feche os olhos, retire os pés do estribo, faça exercícios com os membros superiores; fique de pé sobre o estribo; fique ajoelhado em decúbito dorsal ou ventral sobre o dorso do cavalo, realize um volteio ou faça o cavalo andar e parar várias vezes (8).

Os objetivos do trabalho foram verificar a aquisição de marcos motores em crianças portadoras de Síndrome de Down que realizam a equoterapia e fisioterapia convencional, e descrever as seguintes variáveis: aquisição de marcos motores, equilíbrio estático, equilíbrio dinâmico, força muscular e tempo de tratamento. A hipótese que norteia esta pesquisa é que os indivíduos que obtiveram aquisição de marcos motores primeiramente apresentam melhor equilíbrio estático e dinâmico.

\section{Materiais e métodos}

Este estudo é do tipo transversal e foi resultado do projeto aprovado pela Comissão de Ética da Universidade Cruzeiro do Sul (Protocolo n. 005/2010). Os responsáveis pelas crianças participantes concordaram e assinaram o Termo de Consentimento Livre e Esclarecimento, autorizando a publicação dos dados fornecidos pelos eles, com fins acadêmicos de aprofundamento científico. Todos os indivíduos foram avaliados no mês de abril de 2010.

Os dados foram coletados no Regimento de Policia Montada 9 de Julho (RPMON) e na Associação de Pais e Amigos de Excepcionais em Mogi das Cruzes (Apae) e foi autorizado pelos representantes legais dos locais. A amostra foi constituída por crianças portadoras de Síndrome de Down de ambos os sexos, com idade entre 4 a 13 anos.

Foram selecionadas 33 crianças que já faziam o tratamento fisioterapêutico convencional ou equoterapia desde 1 ano de idade, no mesmo local com, no mínimo, 3 anos de acompanhamento de cada grupo antes da avaliação inicial da pesquisa. No Grupo 1, foram incluídas 19 crianças que realizaram a equoterapia no RPMON; já no Grupo 2 participaram 14 crianças que realizavam a fisioterapia convencional no solo na APAE de Mogi das Cruzes. Foram excluídos os indivíduos com diagnóstico de instabilidade atlanto-axial e os indivíduos que realizavam outros tipos de tratamento fisioterapêutico de diferentes técnicas não propostas nos critérios de inclusão desta pesquisa ou que apresentavam alguma alteração cognitiva impedindo a realização dos testes propostos.

A avaliação foi realizada uma única vez pelos próprios pesquisadores, que se valeram de um questionário biopsicossocial, da escala de desenvolvimento motor (EDM) e da escala de força de Daniels. Os pesquisadores ainda elaboraram questionário contendo dados pessoais, peso, altura, idade em meses em que cumpriu todas as etapas do desenvolvimento motor (rolar, sentar, ajoelhar, semiajoelhar, ficar em pé e marchar) e as doenças associadas.

Inicialmente foi aplicado, pelo mesmo avaliador, um questionário biopsicossocial, elaborado para a pesquisa, contendo 30 questões relativas aos dados da criança (data de nascimento, gênero); condições ligadas à gestação (duração da gravidez); condições ligadas ao nascimento da criança (tipo de parto, peso e altura); condições ligadas ao desenvolvimento neuropsicomotor (idade em que adquiriu controle cervical, sedestação, rolamento, quatro apoios, postura de semiajoelhado e ajoelhado, engatinhamento, ortostatismo, e marcha sozinha); condições clínicas (se apresentavam alteração visual, auditiva, instabilidade atlanto-axial e alteração postural); e condições relacionadas ao tipo de tratamento que realiza (equoterapia ou fisioterapia).

Em seguida, realizou-se o procedimento de avaliação utilizando a Escala do Desenvolvimento Motor (EDM) seguindo a sequência da aplicação descrita por Rosa (9). Essa escala tem o propósito de colocar à disposição de profissionais da saúde e da educação um conjunto de instrumentos de diagnóstico que lhes permite utilizar um método eficaz para realizar estudos transversais e longitudinais com o uso de provas/tarefas construídas sobre princípios técnicos, científicos práticos e coerentes. Consideram-se nesse escala as seguintes variáveis: motricidade fina, motricidade global, equilíbrio estático, esquema corporal, organização espacial e linguagem e organização temporal.

0 teste consiste em realizar atividades motoras conforme a idade cronológica a partir de 2 anos. A partir de cada tarefa cumprida de acordo com o resultado positivo ou negativo obtém-se a idade motora (IM), fator que possibilita calcular o quociente motor geral (QMG) de cada variável, valendo-se da equação $\mathrm{QMG}=\mathrm{IMG} / \mathrm{IC} \times 100$, em que IMG = idade motora geral, e IC = idade cronológica. Para a classificação dos resultados da escala EDM, foram considerados os seguintes escores para o QMG: 130 ou mais equivale a 
muito superior; $120-129$, superior; $110-119$, normal alto; 90-109, normal médio; 80-89. normal baixo; 70-79, inferior; 69 ou menos, muito inferior.

Em seguida, realizaram-se duas baterias de testes para motricidade global e equilíbrio estático; para isso utilizou-se a EDM, de Rosa (9), a fim de determinar a idade motora obtida com base nos pontos alcançados nos testes e o quociente motor obtido, como mencionado anteriormente, pela divisão da idade motora geral pela idade cronológica multiplicada por 100 . Os testes consistem em dez tarefas motoras cada, distribuídas entre $2 \mathrm{e}$ 11 anos, organizadas progressivamente em grau de complexidade, sendo atribuído para cada tarefa, em caso de êxito, um valor correspondente à IM, expressa em meses. Em cada bateria, o teste é interrompido quando a criança não conclui a tarefa com êxito, conforme protocolo. Ao final da aplicação, dependendo do desempenho individual em cada bateria, é atribuída à criança uma determinada idade motora em cada uma das áreas referidas anteriormente (IM1, IM2); depois, é calculada a IMG e QMG da criança. No último momento da avaliação foi utilizada a escala de força de Daniels para quantificar os graus de força muscular de cada criança; atribui-se zero quando não há contração muscular e 5 quando a força muscular é suficiente para vencer a gravidade e uma força mecânica externa. Foi avaliada a força de membros superiores e membros inferiores.

Para avaliar a motricidade global (equilíbrio dinâmico) foram necessários materiais que os pesquisadores disponibilizaram durante as duas baterias de testes para motricidade global e equilíbrio estático, visando à realização dos testes que consistem em dez tarefas motoras; foi utilizado, por exemplo, um banquinho de $15 \mathrm{~cm}$ onde o participante realiza o teste de equilíbrio dinâmico - subir no banco e descer ( 2 anos). Outros materiais foram utilizados com o proposito de testar o equilíbrio, como uma corda de $2 \mathrm{~m}$, caixa de fosforo, cronometro.

As tarefas propostas foram: (a) com os pés juntos, saltar por cima de uma corda estendida sobre o solo, sem impulso, pernas flexionadas ( 3 anos); (b) saltar, sete ou oito vezes sucessivas, sobre o mesmo lugar com as pernas ligeiramente flexionadas (4 anos); (c) com os pés juntos, saltar sem impulso uma altura de $20 \mathrm{~cm}$, sobre uma corda estendida em dois suportes a uma altura de $20 \mathrm{~cm}$ (5 anos); (d) com os olhos abertos, percorrer $2 \mathrm{~m}$ em linha reta, posicionando alternadamente o calcanhar de um pé contra a ponta do outro ( 6 anos); (e) com os olhos abertos, saltar ao longo de uma distância de $5 \mathrm{~m}$ com a perna esquerda, a direita flexionada em ângulo reto com o joelho, os braços relaxados ao longo do corpo e após um descanso de 30 segundos, realizar o mesmo exercício com a outra perna ( 7 anos); (f) com os pés juntos, saltar sem impulso uma altura de $40 \mathrm{~cm}$ sobre uma corda fixada a uma altura $40 \mathrm{~cm}$ (8 anos); (g) saltar no ar, flexionar os joelhos para tocar os calcanhares com as mãos ( 9 anos); (h) com joelho flexionado em ângulo reto, braços relaxados ao longo do corpo, levar uma caixa de fósforos colocada a $25 \mathrm{~cm}$ do pé que repousa no solo até um ponto situado a 5 metros impulsionando-a com o pé (10 anos); (i) saltar sobre uma cadeira de $45 \mathrm{~cm}$ a $50 \mathrm{~cm}$ com uma distância de $50 \mathrm{~cm}$ da mesma enquanto o avaliador sustenta o encosto da cadeira (11 anos).

Na avaliação do equilíbrio estático, foram utilizados os mesmos materiais e um cronômetro, para marcar o tempo de 10 segundos para cada etapa. As atividades propostas foram (a) manter-se imóvel sobre um banco de $15 \mathrm{~cm}$ de altura, pés juntos, braços relaxados ao longo do corpo (2 anos); (b) com os braços ao longo do corpo e pés juntos, apoiar um joelho no chão sem mover os braços ou o outro pé; (c) manter essa posição com o tronco ereto (sem sentar-se sobre o calcanhar) e após 20 segundos de descanso repetir do outro lado (3 anos); (d) com os olhos abertos, pés juntos, mãos apoiadas nas costas, flexionar o tronco em ângulo reto e manter essa posição por 10 segundos (4 anos); (e) manter-se sobre a ponta dos pés, olhos abertos, braços ao longo do corpo, pés e pernas juntos (5 anos); (f) com os olhos abertos, manter-se sobre a perna direita enquanto a outra permanece flexionada em ângulo reto, coxa paralela à direita e ligeiramente em abdução, braços ao longo do corpo (6 anos); ( $g$ ) manter-se sobre o pé esquerdo, a planta do pé direito apoiada na face interna do joelho esquerdo, mãos fixadas nas coxas, olhos abertos, repetir do outro lado. (7 anos); (h) de cócoras, braços estendidos lateralmente, olhos fechados, calcanhares e pés juntos ( 8 anos); (i) com os olhos abertos, mãos nas costas, elevar-se sobre as pontas dos pés e flexionar o tronco em ângulo reto (pernas retas) ( 9 anos); (g) manter-se sobre a ponta dos pés, olhos fechados, braços ao longo do corpo, pés e pernas juntas (10 anos); (h) com 
os olhos fechados, manter-se sobre a perna direita, o joelho esquerdo flexionado em ângulo reto, coxa esquerda paralela à direita e em ligeira abdução, braços ao longo do corpo (11 anos).

Os dados da EDM $(8,9)$ foram tabulados no programa Excel, versão 97-2003. Os dados das variáveis quantitativas referentes à idade cronológica, idade de aquisição dos marcos motores e o tempo de tratamento foram analisados de forma descritiva com média e desvio padrão e com valor de significância de $\mathrm{p}<0,05$.

A partir das variáveis quantitativas do coeficiente motor e do equilíbrio dinâmico e aquisição de marco motor, foi possível fazer a Correlação de Pearson. 0 teste $t$ ou ANOVA seguido de post hoc de Bonferroni foram utilizados para verificar a diferença das variáveis numéricas entre as variáveis categóricas estudadas, tendo como valor de significância p > 0,05. Não houve perda amostral.

Segundo o critério de exclusão, referente à alteração cognitiva, apenas dois praticantes de equoterapia não puderam participar do presente estudo.

\section{Resultados}

Os resultados obtidos no presente estudo, referentes à composição da amostra de 33 crianças portadoras de Síndrome de Down com faixa etária da amostra total variando entre 4 a 13 anos $( \pm 7,72)$, divididas em dois grupos, foram os seguintes: Grupo 1 (equoterapia), composto por 19 crianças, teve média de idade de 7,73 $( \pm 2,25)$; e Grupo 2 (fisioterapia convencional), constituído de 14 crianças, teve média de idade de 7,71 $( \pm 1,43)$. Quanto ao gênero na amostra total, 19 (58,52\%) crianças eram do gênero masculino e 14 (41,18\%), do gênero feminino; constatou-se que nos dois grupos o gênero masculino teve maior percentual, com 10 indivíduos no Grupo 1 (52,63\%) e 9 (64,29\%) no Grupo 2.

Referente ao número de crianças que apresentaram escoliose, seis $(18,18 \%)$ tinham alguma alteração, cinco $(26,32 \%)$ delas realizavam equoterapia e somente uma $(0,14 \%)$ criança que fazia fisioterapia de solo apresentou essa alteração. 0 comprometimento cardíaco esteve presente em seis $(18,18 \%)$ crianças na amostra total; quatro $(21,05 \%)$ delas praticavam equoterapia e duas $(14,28 \%)$ realizavam fisioterapia.
Referente à acuidade visual, a maior parte da amostra referiu apresentar deficiência; das 33 crianças, 18 (54,55\%) apresentam alguma alteração e 15 (45,45\%) relataram não apresentar nenhum problema de visão; porém, quando realizamos a f (frequência), notou-se que entre as 19 crianças que faziam equoterapia, nove (47,37\%) apresentavam algum tipo de alteração visual, já entre as crianças que realizavam a fisioterapia, nove $(64,29 \%)$ apresentam deficit visual.

A alteração auditiva esteve presente em cinco $(15,15 \%)$ crianças na amostra total, duas $(10,52 \%)$ delas praticavam equoterapia e três $(21,42 \%)$ estavam no grupo fisioterapia.

Em relação à utilização da órtese, em toda a amostra esse item foi muito insignificante, uma vez que apenas uma criança $(3,03 \%)$, do grupo equoterapia, faz uso da mesma.

A respeito do tempo de tratamento, expresso em meses, observou-se que as crianças que realizam fisioterapia obtiveram um maior tempo de tratamento, $27( \pm 10,80)$, ao passo que o grupo equoterapia apresentou 18,10 $\pm(11,13), p=0,04$.

Efetivou-se análise descritiva das aquisições motoras (controle cervical, rolamento, transição deitado para sentado, ortostatismo e marcha) e valor de p obtido entre os níveis de adesão (amostra total, equoterapia e fisioterapia) descritos na Tabela 1. A idade é expressa em anos. $\mathrm{O}$ valor de $\mathrm{T}$ foi aplicado para os grupos equoterapia e fisioterapia. Foi possível observar que quase todas as aquisições das etapas motoras ocorreu primeiramente nos indivíduos que realizavam fisioterapia, exceto o rolamento que se iniciou primeiramente em crianças que realizam a equoterapia. E apenas o ortostatismo apresentou significância estatística $p=0,04$.

Conforme a Tabela 2 verificou-se uma correlação moderada entre QMG do equilíbrio dinâmico e rolamento no grupo fisioterapia, pois se trata de uma correlação inversamente proporcional, tendo maior relevância em nosso estudo. Quanto à correlação entre QMG do equilíbrio dinâmico e ortostatismo, houve uma correlação forte.

De acordo com a Tabela 3, verifica-se que tanto o equilíbrio estático como o dinâmico, encontra-se melhor em relação à modalidade terapêutica fisioterapia, no grupo que realizou fisioterapia, tendo como referência os valores dos escores QMG. 0 grupo equoterapia foi considerado normal baixo para equilíbrio estático, e muito inferior para equilíbrio dinâmico, já o grupo fisioterapia foi normal médio para equilíbrios estático e dinâmico testados. 
Tabela 1 - Aquisição de marcos motores

\begin{tabular}{lcccc}
\hline & Amostra total média ( \pm d.p.) & Equoterapia média ( \pm d.p.) & Fisioterapiamédia ( \pm d.p.) & Test T p \\
\hline Controle Cervical & $7,09(2,30)$ & $7,42(2,69)$ & $6,57(1,50)$ & 0,16 \\
Rolar & $10,09(4,65)$ & $9,94(6,15)$ & $10,28(0,91)$ & 0,80 \\
$\begin{array}{l}\text { Transição deitado } \\
\text { para sentado }\end{array}$ & $14,24(4,91)$ & $14,57(6,44)$ & $13,78(1,25)$ & 0,60 \\
Ortostatismo & $20,66(8,11)$ & $22,84(9,70)$ & $17,71(3,91)$ & 0,04 \\
Marcha & $26,42(7,28)$ & $27,05(9,49)$ & $25,57(2,10)$ & 0,98 \\
\hline
\end{tabular}

Fonte: Dados da pesquisa.

Nota: $p<0,05$ valor de significância.

Tabela 2 - Correlação de Pearson entre 0 QMG do equilíbrio dinâmico e aquisições de marcos motores quanto ao rolamento, ao ortostatismo e à marcha no grupo fisioterapia

\begin{tabular}{lc}
\hline Variável & Correlação $r$ \\
\hline QMG Eq. Dinâmico vs. Rolamento & $-0,50^{*}$ \\
QMG Eq. Dinâmico vs. Ortostatismo & $0,74^{\star *}$ \\
QMG Eq. Dinâmico vs. Marcha & $0,62^{*}$ \\
\hline
\end{tabular}

Legenda: $Q M G$ = Quociente Motor Geral; Eq. = Equilíbrio.

Fonte: Dados da pesquisa.

Nota: * $=$ Correlação moderada $(R>0,40) ;{ }^{* *}=$ Correlação forte $(R>0,71)$.

Tabela 3 - Valores de p obtidos na comparação entre os grupos equoterapia e fisioterapia referente ao equilíbrio estático e dinâmico

\begin{tabular}{lccc}
\hline & Equoterapia média ( \pm d.p.) & Fisioterapia média $( \pm$ d.p.) & p \\
\hline Eq. estático & $81,99(12,87)$ & $96,60(11,72)$ & 0,002 \\
Eq. dinâmico & $68,39(15,81)$ & $91,86(13,65)$ & 0,0001 \\
\hline
\end{tabular}

Legenda: $E q$ = equilíbrio; d.p. = desvio padrão.

Fonte: Dados da pesquisa.

Nota: Valor de significância $p<0,05$.

\section{Discussão}

Considerando os fatores relacionados à motricidade avaliados com base na Escala EDM, observa-se que o equilíbrio dinâmico e estático variou de inferior à normal médio, conforme os escores obtidos. Quanto aos resultados encontrados referentes aos marcos motores observou-se que há um atraso importante no desenvolvimento motor em $100 \%$ da amostra. As crianças que participaram desta pesquisa apresentaram algumas características normalmente esperadas em pacientes portadores de Síndrome de Down, entre elas estão: a hipotonia e a alteração quanto à acuidade visual. Porém, algumas características da amostra do estudo contradizem a literatura, sendo elas alteração postural, acuidade auditiva e o comprometimento cardíaco.

O desenvolvimento motor é um processo contínuo e demorado e, pelo fato de as mudanças mais 
acentuadas ocorrerem nos primeiros anos de vida, existe uma tendência em se considerar o aprendizado do desenvolvimento motor como sendo apenas o estudo da criança, basicamente pela aquisição, estabilização e diversificação das habilidades básicas (10). De modo geral, apesar dos baixos resultados motores atingidos pelas crianças com Síndrome de Down, as pesquisas mostram que programas de estimulação precoce e intervenção são capazes de fazê-las atingir níveis motores mais satisfatórios $(11,12)$.

0 controle cervical é a primeira aquisição motora de um recém-nascido com desenvolvimento neuropsicomotor normal; a criança normal, ao ser colocada em decúbito ventral, consegue levantar a cabeça e manter a posição durante alguns segundos; entretanto, somente aos 4 meses, se colocada sentada é capaz de manter a cabeça firme (13). Já as crianças investigadas neste estudo alcançaram o controle cervical em média aos 7,09 meses na amostra geral (Tabela 1). Isso provavelmente se deve ao fato de que a criança com Síndrome de Down, ao nascimento, apresenta fraqueza da musculatura do pescoço, não conseguindo vencer a força da gravidade e dificultando o posicionamento estático de sua cabeça. Esse atraso, portanto, tem relação com o tônus hipotônico do recém-nascido, que adota posturas em extensão quando em supino, em vez de assumir postura flexora, característica do recém-nascido a termo (13).

0 rolamento em uma criança normal inicia-se por volta dos 5 meses (14), ao passo que no presente estudo, a idade média para a mesma aquisição motora foi de 10,09 meses.

0 sentar independente ocorre em média aos 10 meses de idade em crianças com desenvolvimento motor normal, enquanto que Pueschel (14) estima que o sentar inicia-se geralmente aos 9 meses nessas crianças; para as crianças desta pesquisa a média para a aquisição do sentar foi de 14,54 meses. Tal fato pode ser explicado pelo processo de maturação que está relacionado com o grau de mielinização, arborização e formação de sinapses das células nervosas do Sistema Nervoso Central, que aos poucos inibem as atividades reflexas primitivas, passando para uma fase de transição e, por último, assumindo o controle voluntário dessa atividade, com o desenvolvimento das reações de retificação, proteção e equilíbrio (16). Corroborando essa afirmação, a capacidade do bebê e da criança em realizar diferentes atividades cada vez mais complexas requer uma integração sensorial (IS) e motora durante os primeiros anos de vida, a mielinização do córtex proporciona ganho progressivo do controle motor (17).

Para que o desenvolvimento motor ocorra, a criança precisa passar por momentos de experimentação e erro, aprimorando as habilidades motoras; assim, o tratamento equoterápico tem grande influência nesse aspecto, uma vez que na equoterapia observa-se um ajuste tônico, marcado pelo movimento automático de adaptação ritmado, o que facilita as informações proprioceptivas (18). Apesar de o equilíbrio ter sido mais evidenciado na fisioterapia do que na equoterapia, notou-se nos testes que as crianças que fazem equoterapia apresentam ajustes posturais e reações adaptativas mais rápidas, porém não tão eficazes.

A passagem de sentado para em pé geralmente ocorre por volta dos 8 ou 10 meses de idade em crianças normais (3); nesta pesquisa, entre as crianças com Síndrome de Down, essa transição postural foi observada somente aos 11 meses. No presente estudo, a faixa etária de aquisição para a posição bípede foi de 20,66 meses aproximadamente (19).

A criança deve ser treinada para a posição em pé desde a baixa idade, quando houver riscos de apresentar atraso no desenvolvimento motor, para que aprenda a produzir e controlar as forças musculares, assim como dominar os efeitos da interação de rotação de membros. 0 ato de ficar em pé torna-se, então, equilibrado e econômico em relação ao consumo de energia (6). No estudo, observou-se que a idade de inicio para o ortostatismo foi menor no grupo fisioterapia, ficando comprovado estatisticamente um melhor escore quanto ao equilíbrio dinâmico.

A postura em pé favorece novas experiências, enviando ao SNC as informações da postura correta; a partir daí, o corpo é alinhado biomecanicamente por meio dos ajustes posturais (20). Entretanto, essa afirmativa mostra a importância da quantidade e da qualidade dos estímulos dados a essas crianças tanto em uma terapia convencional como na equoterapia. Corroborando esse dado, o fato de as crianças repetirem e praticarem as atividades motoras durante a sua movimentação espontânea de interação com o meio ambiente contribui para a formação dos mecanismos plásticos do SNC e reforça seus engramas motores para a função (21). Embora crianças sejam capazes de manter a posição ereta a partir de 1 ano, a manutenção dessa posição parece ser continuamente refinada ao longo da primeira década de vida (22) e o deficit de equilíbrio na criança com Síndrome de Down é importante e pode persistir até a adolescência (23). Tal 
fato pode justificar o baixo escore obtido no equilíbrio estático das crianças que fizeram parte do estudo, uma vez que a posição ortostática depende de ajustes e estratégias posturais.

O deficit de equilíbrio pode ser explicado pelo fato de crianças com Síndrome de Down oscilarem por causa da dificuldade em captar as informações sensoriais que determinam a posição do corpo no espaço e a velocidade com que o corpo está se movendo (24). No presente estudo, observou-se que a maior parte das crianças apresentou alteração visual, assim confirmando a literatura, sabe-se que para um bom controle postural é necessária a integração harmônica dos três sistemas (visual, vestibular e somatossensitivo), e no estudo evidenciou-se que essa interação não está ocorrendo. Um estudo realizado em 2005 avaliou indivíduos portadores de deficiência visual e indivíduos com visão normal, em uma plataforma de força. Os autores observaram que os deficientes visuais apresentaram maior oscilação laterolateral, porém no sentido anteroposterior não observaram diferença significativa entre os grupos (25). Sendo assim, o equilíbrio dinâmico também se encontra alterado, pois essa oscilação impede que ocorra um bom desempenho no movimento.

Apesar de a fisioterapia convencional ter se mostrando eficiente em relação ao equilíbrio, notou-se que o ambiente tem grandes influências na terapia, como pode ser observado pelos pesquisadores do estudo e relatado pelos responsáveis, as crianças que realizam equoterapia apresentaram uma maior interação entre o ambiente, o animal e o terapeuta adquirindo uma melhor sociabilização. Já nas sessões de fisioterapia convencional, geralmente o tratamento é individualizado, o contato é apenas entre terapeuta e paciente.

A aquisição da marcha independente inicia-se geralmente aos 13 meses em uma criança neurologicamente normal, ao passo que em indivíduos com Síndrome de Down, a marcha inicia-se por volta dos 20 meses (14), sendo que no estudo verificou-se que a idade para aquisição da marcha foi de 26,42 meses.

A fisioterapia normalmente centra-se na mobilidade, inclusive na pré-marcha, como dar impulso da posição ajoelhada para em pé (26). Possivelmente essa seja a razão para a fisioterapia ter apresentado melhor desempenho em relação ao equilíbrio dinâmico.

A hiperfrouxidão ligamentar com a hipotonia resulta na falta de rotação de tronco, e consequentemente no atraso e na imaturidade da aquisição da marcha, legitimando o deficit de equilíbrio dinâmico presente nesses indivíduos do estudo (19). 0 estudo relatou que a eficiência dinâmica da marcha é resultado da integração sensorial dos sistemas visual, vestibular, somatossensitivo, tátil e da força muscular adequada, boa mobilidade articular e controle neuromuscular eficiente. A manutenção do equilíbrio é adquirida segundo um conjunto de mecanismos interligados, tais como elasticidade dos ligamentos, tendões e músculos que proporcionam estabilização das articulações $(27,28)$. Com isso, o equilíbrio dinâmico torna-se ineficaz como comprovado no estudo.

Os deficit do controle motor juntamente e da força muscular podem ser os principais fatores responsáveis pelo atraso da aquisição da deambulação independente do portador da Síndrome de Down. A falta de controle do tronco dificulta a aquisição do equilíbrio (6). Nos indivíduos que fizeram parte do estudo, a força muscular variou entre 4 e 5; no entanto, não houve significância quando comparado ao equilíbrio dinâmico ou estático.

No presente estudo, observou-se que os indivíduos do grupo que realizou fisioterapia convencional o tempo de tratamento foi maior do que no grupo que realizou equoterapia e o equilíbrio dinâmico foi significante no grupo que realizou fisioterapia; isso demonstra que essa modalidade de fisioterapia realizada por um período de tempo longo influencia positivamente na aquisição do equilíbrio dinâmico.

Em um estudo sobre os benefícios da equoterapia no desenvolvimento motor de uma criança portadora de Síndrome de Down, compararam-se a avaliação pré e a pós-tratamento; notou-se melhora no equilíbrio a partir da décima sessão de equoterapia, porém não chegando ao que seria normal para a sua idade cronológica (29). Desse modo, pode-se mencionar a relação entre custo e beneficio, pois a equoterapia é uma modalidade com custo elevado, sendo realizada apenas uma sessão por semana, conforme relatado pelos responsáveis das instituições onde ocorreu o estudo. Já a fisioterapia, além de ser realizada por um tempo maior de tratamento, permite duas ou mais sessões por semana. Constatou-se, ao longo desta pesquisa, que os indivíduos portadores de Síndrome de Down possuem várias deficiências motoras, atraso no desenvolvimento motor e neurológico, hipotonia muscular, diminuição de força muscular, e deficit de equilíbrio estático e dinâmico, entre outros distúrbios que influenciam no convívio social.

Sugerimos novos estudos com protocolos de tratamento e acompanhamento longitudinal a fim de investigar possíveis benefícios da equoterapia e da fisioterapia convencional. 


\section{Conclusão}

Na amostra composta por crianças com Síndrome de Down, todos apresentaram atraso no desenvolvimento motor. A equoterapia e a fisioterapia convencional influenciaram na aquisição de marcos motores em portadores de Síndrome de Down; em ambos os grupos houve melhora nesse aspecto, sendo mais evidente no grupo da fisioterapia.

Considerando o equilíbrio estático e o dinâmico e tendo como referencia os valores dos escores $\mathrm{QMG}, \mathrm{o}$ grupo 1 da equoterapia foi considerado normal baixo para equilíbrio estático e muito inferior para equilíbrio dinâmico; o grupo fisioterapia, por sua vez, foi considerado normal médio para ambos os equilíbrios estáticos e dinâmicos testados.

O tempo de tratamento do grupo de fisioterapia foi maior que o grupo de equoterapia.

Na avaliação da força muscular com uso da escala de Daniels, todos apresentaram força de 4 e 5 considerando boa e excelente para o grupo estudado.

\section{Referências}

1. Schwartzman SJ. Síndrome de Down. São Paulo: Editora Mackenzie; 2000.

2. Barreto F, Gomes G, Silva IAS, Gomes LM. Proposta de um programa multidisciplinar para portador de Síndrome de Down, através de atividades da equoterapia, a partir dos princípios da motricidade humana. Rev Fit Perf J. 2007;6(2):82-8.

3. Shepherd RB. Desenvolvimento da motricidade da habilidade motora. In: Shepherd RB, organizador. Fisioterapia pediátrica. 2. ed. São Paulo: Santos; 1998. p. 9-42.

4. Bonvicine C, Quibáo EF, Silva PN, Asa SKP, Gaetan ESM. Aquisição do controle de cabeça em lactentes nascidos pré-termo e a termo. Fisioter pesqui. 2005;12(2):45-50.

5. Allison L, Fuller K. Equilíbrio e desordens vestibulares. In: Umphred DA, organizador. Reabilitação neurológica. 4. ed. Barueri: Manole; 2004. p. 648-95.

6. Shepherd, RB. Fisioterapia em Pediatria. 3. ed. São Paulo: Santos; 2006.

7. Medeiros M, Dias E. Equoterapia: bases e fundamentos. Rio de Janeiro: Revinter; 2002.
8. Uzun ALL. Equoterapia: aplicação em distúrbios do equilíbrio. São Paulo: Vetor; 2005.

9. Rosa F Neto. Manual de avaliação motora. Porto Alegre: Artmed; 2002.

10. Tani G, Manoel EJ, Kokubun E, Proença JE. Educação Física escolar: fundamentos de uma abordagem desenvolvimentista. São Paulo: E.P.U.; 1988.

11. Lorenzini M. Brincando a brincadeira com a criança deficiente. Barueri: Manole; 2002.

12. Sanches PA, Martinez MR, Peñalver IV. A psicomotricidade na educação infantil - uma prática preventiva e educativa. Porto Alegre: Artmed; 2003.

13. Funayama CAR. Aspectos neurológicos da síndrome de Down. Temas desenvolv. 2002;11(61):40-4.

14. Pueschel SM, organizador. Síndrome de Down: guia para pais e educadores. São Paulo: Papirus; 1993.

15. Mustacchi Z, Peres S. Genética baseada em evidências: síndromes e heranças. São Paulo: CID Editora; 2000.

16. Olhweiler L, Silva AR, Rotta NT. Estudo dos reflexos primitivos em pacientes recém-nascidos pré-termo normais no primeiro ano de vida. Arq Neuropsiquiatr. 2005;63(2-A):294-7.

17. Godzicki B, Silva PA, Blume LB. Aquisição do sentar independente na Síndrome de Down utilizando o balanço. Fisioter Mov. 2010;23(1):73-81.

18. Cirillo LC. Equoterapia. Brasília: ANDE-BRASIL; 2001.

19. Tecklin JS. Fisioterapia pediátrica. 3. ed. Porto Alegre: Artmed, 2002.

20. Szadokoski MA. Importância do ortostatismo na disfunção neuromotora com seqüela motora grave para a formação da cognição [TCC]. Foz do Iguaçu: Faculdade União das Américas; 2005 [acesso 3 out 2006]. Disponível em: http://www.wgate.com.br/conteudo/ medicinaesaude/fisioterapia/neuro/ortostatismo/ ortostatismo_melissa.htm

21. Mattos M. Bellani CDF. A importância da estimulação precoce em bebês portadores de Síndrome de Down: revisão de literatura. Rev Bras Terap e Saúde. 2010;1(1):51-63.

22. Figura F, Cama G, Capranica L, Guidetti L, Pulejo C. Assessment of static balcance in children. J Sports Med Phys Fitness. 1991;31(2):235-42. 
23. Sarro KJ, Salina ME. Estudo de alguns fatores que influenciam no desenvolvimento das aquisições motoras de crianças portadoras de Síndrome de Down em tratamento fisioterápico. Fisioter Mov. 1999;13(1):93-106.

24. Vullerme N, Marin L, Debu B. Assessment of static postural control in teenagers with Down Syndrome. Adap Phys Act Quart. 2001;18(4):417-33.

25. Oliveira DN, Barreto RR. Avaliação do equilíbrio estático em deficientes visuais adquiridos. Rev neurociênc. 2005;13(3):122-7.

26. Ratliffe KT. Fisioterapia na clínica pediátrica: guia para a equipe de fisioterapeutas. São Paulo: Santos; 2002.

27. Westcoot SL, Goulet C. Sistema neuromuscular: estruturas, funções diagnóstico e avaliação. In: Effgen SK, organizador. Fisioterapia pediátrica: atendendo às necessidades das crianças. Rio de Janeiro: Guanabara Koogan; 2007.
28. Souto JN, Lima EAM, Paes JB, Bento MCC, Torquato JA, Saikai GPN, et al. Desenvolvimento neuropsicomotor de crianças institucionalizadas da zona leste da cidade de São Paulo. Temas desenvolv. 2008;16(94):198-202.

29. Pereira PA, Leandro DF. Estudo de caso: os benefícios da equoterapia no desenvolvimento motor em uma criança portadora de Síndrome de Down. Revista Inspirar. 2009;1(2):20-3.

Recebido: 07/09/2012

Received: 09/07/2012

Aprovado: 16/06/2013

Approved: 06/16/2013 